\title{
EFEITO DA ADIÇÃO DE DIFERENTES CONCENTRAÇÕES DE DIACETADO DE CLOREXIDINA NAS PROPRIEDADES FÍSICAS DE UM SELANTE DE FÓSSULAS E FISSURAS
}

\author{
Marina B. Tersi ${ }^{\star}$, Tabatha M.T. Garcia, Kamila R. Kantovitz, Regina M. Puppin-Rontani, Fernanda M. Pascon
}

\section{Resumo}

O objetivo do estudo foi avaliar o efeito da adição de diferentes concentrações de clorexidina $(\mathrm{CHX})$ a um selante resinoso quanto às propriedades físicas. Espécimes $(7 \times 2 \times 1 \mathrm{~mm}$ - teste de resistência à flexão e módulo de elasticidade; $5 \times 1 \mathrm{~mm}$ - teste softening/amolecimento) foram preparados e distribuídos nos grupos: Selante Resinoso Comercial (controle - S), S + 0,1\% de CHX (SC1) e S + 0,2\% de CHX (SC2). Após a adição de CHX, o material foi misturado, inserido em matrizes e fotoativado de acordo com as recomendações do fabricante. O teste de resistência à flexão foi conduzido em máquina de ensaio universal Instron, com carga de $50 \mathrm{~N}$ e velocidade de $0,5 \mathrm{~mm} / \mathrm{min}$ até a fratura. Para a determinação do softening foram determinadas a dureza Knoop inicial (KHN1) dos espécimes (5 edentações com carga de $10 \mathrm{gF} / 5 \mathrm{~s}$ ). A média das 5 edentações foi considerada para análise estatística. Em seguida, os espécimes foram imersos individualmente em $1 \mathrm{~mL}$ de etanol absoluto por $24 \mathrm{~h}$ a $37^{\circ} \mathrm{C}$. Após este período, obteve-se a dureza Knoop final (KHN2) seguindo o mesmo procedimento descrito anteriormente. O amolecimento foi determinado em porcentagem seguindo a equação: Softening test $=100-[(\mathrm{KHN} 2 / \mathrm{KHN1}) \times 100]$. Os dados foram submetidos ao teste de normalidade, ANOVA e Tukey ( $\alpha=5 \%$ ).

Palavras-chave: Clorexidina, selante de fossas e fissuras, teste de flexão, teste de dureza

\section{Introdução}

A cárie dentária é uma doença crônica observada em crianças e adolescentes em todo o mundo. As superfícies proximais, oclusais e margens gengivais apresentam maior susceptibilidade ao desenvolvimento de lesão cariosa devido ao acúmulo de biofilme. Para o controle das lesões cariosas nessas superfícies podem ser utilizados selantes de fóssulas e fissuras como estratégia preventiva eficaz em pacientes de alto risco à cárie e em idade escolar. Entretanto, a capacidade do selante para suportar as forças mastigatórias depende das propriedades físicas, mecânicas, químicas e biológicas. Assim, observa-se que a adição de agentes antimicrobianos aos materiais resinosos poderia diminuir ou impedir a adesão de biofilme na superfície do material e assim evitar novos episódios de desmineralização dos tecidos dentários.

\section{Resultados e Discussão}

Teste de Resistência à Flexão e Módulo de Elasticidade:

1. Preparo de matrizes de silicone $(7 \mathrm{~mm} \times 2 \mathrm{~mm} \times 1 \mathrm{~mm})$ $(n=12)$;

2. Pesagem, incorporação e homogeneização de $0,1 \%$ e $0,2 \%$ de $\mathrm{CHX}$ ao selante comercial;

3. Inserção dos materiais nas matrizes e fotoativação por 40 segundos;

4. Impermeabilização dos espécimes e armazenamento por 24 horas;

5. Realização do teste de resistência à flexão em máquina de ensaio universal Instron, com carga de $50 \mathrm{~N}$ e velocidade de $0,5 \mathrm{~mm} / \mathrm{min}$ até a fratura.

Metodologia para teste softening/amolecimento:

1. Preparo de matrizes de silicone $(5 \mathrm{~mm} \times 1 \mathrm{~mm})(\mathrm{n}=10)$;

2. Pesagem, incorporação e homogeneização de $0,1 \%$ e $0,2 \%$ de $\mathrm{CHX}$ ao selante comercial;

3. Inserção dos materiais nas matrizes e fotoativação por 40 segundos;

4. Impermeabilização dos espécimes e armazenamento por $24 \mathrm{~h}$;

5. Determinação da dureza Knoop (antes-KHN1 e depois-KHN2): foram realizadas 5 edentações em cada espécime com carga $10 \mathrm{gF} / 5 \mathrm{~s}$;
6. Imersão dos espécimes em $1 \mathrm{~mL}$ de alcool absoluto a $37^{\circ} \mathrm{C}$ por $24 \mathrm{~h}$;

7. Determinação da porcentagem de amolecimento, utilizando a seguinte fórmula: Softening $=100$ [(KHN2 / KHN1) x100].

Tabela 1. Médias $( \pm D P)$ dos valores do módulo de elasticidade e resistência à flexão dos materiais avaliados

\begin{tabular}{ccc}
\hline GRUPOS & $\begin{array}{c}\text { Módulo de } \\
\text { Elasticidade (GPA) }\end{array}$ & $\begin{array}{c}\text { Resistência à } \\
\text { Flexão (MPA) }\end{array}$ \\
\hline $\mathrm{S}$ & $2,24 \pm 0,45 \mathrm{a}$ & $113,1 \pm 15,3 \mathrm{a}$ \\
$\mathrm{SC} 1$ & $1,41 \pm 0,73 \mathrm{~b}$ & $75,6 \pm 27,4 \mathrm{~b}$ \\
$\mathrm{SC} 2$ & $1,47 \pm 0,53 \mathrm{~b}$ & $94,8 \pm 32,0 \mathrm{ab}$ \\
\hline Letras minúsculas iguais representam ausência de diferença significativa entre os grupos
\end{tabular}
estudados.

$\mathrm{S}=$ Selante$; \mathrm{SC} 1=$ Selante $+0,1 \%$ de Clorexidina $; \mathrm{SC} 2=$ Selante $+0,2 \%$ de Clorexidina

Tabela 2. Médias $( \pm D P)$ dos valores de dureza antes e após a imersão em álcool absoluto e porcentagem de softening

\begin{tabular}{cccc}
\hline GRUPOS & Dureza 1 & Dureza 2 & Softening (\%) \\
\hline S & $17,64 \pm 1,61 \mathrm{~b}$ & $10,21 \pm 0,23 \mathrm{a}$ & $41,71 \pm 5,04 \mathrm{~b}$ \\
$\mathrm{SC} 1$ & $19,93 \pm 0,33 \mathrm{a}$ & $10,24 \pm 0,25 \mathrm{a}$ & $48,58 \pm 1,67 \mathrm{a}$ \\
$\mathrm{SC} 2$ & $19,45 \pm 0,42 \mathrm{a}$ & $10,15 \pm 0,26 \mathrm{a}$ & $47,50 \pm 1,47 \mathrm{a}$ \\
\hline Letras minúsculas diferentes em colunas representam diferença significativa entre os \\
grupos estudados. \\
S=Selante; $\mathrm{SC} 1$ = Selante + $0,1 \%$ de Clorexidina; $\mathrm{SC} 2$ = Selante $+0,2 \%$ de Clorexidina
\end{tabular}

\section{Conclusões}

Conclui-se que a adição de $0,1 \%$ e $0,2 \%$ de $\mathrm{CHX}$ diminuiu módulo de elasticidade do material e somente com a adição de $0,1 \%$ houve diminuição da resistência à flexão e para ambas as concentrações houve amolecimento do material.

\section{Agradecimentos}

Ao PIBIC/UNICAMP pela bolsa de estudos concedida.

1. Ahovuo-Saloranta A, Forss H, Hiiri A, Nordblad A, Mäkelä M. Pit and fissure sealants versus fluoride varnishes for preventing dental decay in the permanent teeth of children and adolescents. Cochrane Database Syst Rev. 2016 Jan 18;(1):CD003067. doi: 10.1002/14651858.CD003067.

2. Inagaki LT, Dainezi VB, Alonso RC, Paula AB, Garcia-Godoy F, Puppin-Rontan RM, Pascon FM. Evaluation of sorption/solubility, cross-link density, flexural strength and elastic modulus of experimental resin blends with chlorhexidine. $J$ Dent. 2016;49:40-5. 